\title{
Evaluating the Distance Learning Experience from the Point of View of College Members and Students at Aqaba University College
}

\author{
Ahed Hani Almsaiden ${ }^{1 *}$, Taha Ali Hussein ${ }^{2}$ \\ ${ }^{1}$ Assistant Professor, Al Balqa Applied University, Department of Basic Sciences, Aqaba-Jordan \\ ${ }^{2}$ Professor, The World Islamic University, College of Education Sciences, Department of Curriculum and Instructions, Amman, Jordan
}

\section{Abstract}

This study aimed to evaluate the distance learning experience from the point of view of college members and students at Aqaba University College. The study adopted the descriptive research methodology. The sample of the study consisted of all faculty members in the college who were (42) teachers, in addition to (84) students who were selected randomly from (333) male and female students. Moreover, two questionnaires were prepared, one was for the teachers and another was for the students. The results showed a grade of rating (average) in evaluating the distance learning experience from the viewpoint of the teachers and students at the college. It also showed that the male students' evaluation of the experience was better than the female one. In light of the results, the study recommended to develop the distance learning by providing the appropriate infrastructure. Furthermore, providing the infrastructure and using the available technological means for communication and conducting other studies on this problem

Keywords: Distance learning, college members, students, University College.

\section{INTRODUCTION}

The great developments that the world is going through today in various fields, such as communications, technologies, means of learning and other technological revolutions, have had a clear impact in developing the foundations, methods and strategies of teaching. This was clearly demonstrated by the development of educational systems, with their different philosophy and orientations. Al-Azzam (2017) mentioned that the educational system cannot ignore the role and impact of technology and techniques on the outcomes of the education process. The development of the educational infrastructure has become a prerequisite to keep the progress, as is the case in developing the capabilities and knowledge of human resources to be able to provide educational services efficiently and effectively. Many technology companies seek to develop electronic systems and programs to provide the required services in an optimal way, and here the important role of educational institutions to work alongside educational program designers to ensure that they include a distinct virtual classroom environment. Despite the extraordinary efforts made by the Higher Education Department to develop distance learning, it still faces multiple problems and difficulties, which have led to this experience being unprofessional in some aspects. In order to know the viewpoint of university students and their teachers in evaluating the distance learning experience, this study came.

\section{LiteratURE REVIEW}

Several studies have been conducted in the field of distance learning and among these studies is the study of Basilia and Vavadze, which aimed to reveal the capabilities of schools to provide distance education services. The study sample consisted of (950) male and female students from private schools in (Georgia). The results showed the schools' success in moving to a distance learning experience. However, the study confirmed that traditional education is more effective (Basilaia \& Kvavadz, 2020). Al-Zboon (2020) conducted a study which aimed to reveal the effectiveness of distance learning compared to direct education in the achievement of first-year secondary students in Arabic language in Jordan. The sample consisted of (35) students, and their achievement in the first and second semesters was compared in the lessons of grammar, morphology, rhetoric, criticism, and literary issues. The results showed the superiority of the direct teaching method compared to distance learning, and the study recommended the use of the blended learning method which is a combination of the two methods: traditional and electronic, and also recommended re-designing the content to suit distance learning. Also, Al-Mahmadi (2018) carried a study to evaluate the reality of using the e-learning system (EMES) in the distance education program in the distance learning technology at King Abdulaziz University from the

Corresponding Author e-mail: ahed.soudi@bau.edu.jo, Mobile: +962 790327252

https://orcid.org/0000-0003-2336-8310

How to cite this article: Almsaiden AH, Hussein TA, (2021). Evaluating the Distance Learning Experience from the Point of View of College Members and Students at Aqaba University College. Pegem Journal of Education and Instruction, Vol. 11, No. 4, 2021, 353-359

Source of support: Nil

Conflict of interest: None.

DOI: $10.47750 /$ pegegog.11.04.34

Received: 12.07 .2021

Accepted: 20.09.2021 Publication: 01.10.2021 
students' point of view. The study sample consisted of (570) students, and (115) teachers. The researcher followed the descriptive approach and used a questionnaire to collect data. The study concluded that there are obstacles faced by distance education which centered on the infrastructure, and the lack of knowledge of some of the techniques among students and faculty members.

Kamal (2002) assured on the necessity of technology in education, because of its advantages in unifying classes and class dimensions in education to get rid of classroom congestion and reduce individual differences, as well as, its great importance in building and refining personality by encouraging students to participate and express their opinions in interview or meeting. As for distance learning, it is a mechanism and method in which the classroom is virtual in which the educational institution, the teachers and the students meet with an electronic program in which everyone interacts, as the educational material is clearly reviewed and which can be attended at any time later.

Distance learning is characterized by the absence of direct communication between the participants, and in some cases there is no visual communication between the teacher and the student as the teacher prepares the material and publishes it, and feel it enough to focus to watch the entire content (Al-Akhras, 2018). Also, distance learning provides the principle of equal educational opportunities, easy access to information and knowledge, getting rid of the factor of fear and anxiety, opening the way for students to express their ideas and opinions, and their ability to investigate and acquire information better than in traditional classrooms (Visande, 2014).

Distance learning achieves excellent results for students in their achievement and follow-up, but it is not effective in some disciplines such as medical and engineering disciplines, because they need to conduct laboratory experiments, and some kind of interaction between students on the one hand and between them and their teacher on the other hand (Al-Hassan, 2014). Some basic criteria have emerged in learning that reflect the quality and efficiency of the educational process, but these criteria cannot be measured as a hypothetical component. It has been pointed out that the problem in this type of learning is due to the weak technical and electronic expertise of the teacher and student, the weakness of scientific and academic organization, and the poor level of comprehension. Many students have, because there is a huge amount of information, which in turn needs basic ingredients and focused discussions to achieve the required comprehension (Awad \& Halles, 2015).

The emergence of the Corona pandemic was the main reason for educational institutions to switch to distance learning; the imposition of the ban had an impact on the adoption of programs in line with this type of learning as many of these programs were devised to meet the requirements of the stage. However, some educational institutions faced a lack of infrastructure such as the availability of computer equipment and access to the Internet, as well as, the imposition of ban laws which prevented many teachers from accessing educational institutions (Affouneh et al., 2020).

In light of the Corona pandemic, educational institutions have started using electronic means to implement a campaign to provide educational services remotely to ensure a successful and effective process. The responsible authorities have been keen to activate some educational platforms and programs aimed at creating virtual classrooms to enable the student and teacher to participate effectively (Yulia, 2020).

A study by Belbeisi (2017) aimed to know the effectiveness of Al-Quds Open University students in using distance learning techniques and skills. The sample consisted of 5\% of the study population of (1890) male and female students, which were taken randomly, and a special questionnaire was used according to the Likert scale of five. The results showed the strong role of supervisors in using appropriate methods of distance learning and the students' weakness in using modern technology with the presence of female superiority at the expense of males. The results also indicated the increased effectiveness of students in using this skill with the advancement of academic levels, and the variation in specializations such as the superiority of computer students.

Molla's study (2016) aimed at evaluating the distance education experience at the University of Malaysia and the College of Education for Girls according to quality standards taken from the Quality Assurance Agency for Higher Education in Britain. The researcher used the qualitative approach in analyzing the documents, and the descriptive approach in using a special questionnaire on the study sample. The study sample for the Malaysian University consisted of documents in the university and some studies that dealt with the experience. As for the experience of the College of Education for Girls, the entire study population was taken from the college students. The results showed the most important quality factors in distance education, with the correct preparation of the infrastructure, the provision of human, financial, technical and administrative expertise, the provision of quality centers, and the multiplicity of technical media.

By reviewing previous studies, it is clear that they all dealt with distance learning in terms of revealing the capabilities of schools in providing services of this type of learning, in terms of revealing the effectiveness of distance learning, in terms of the reality of using e-learning, in terms of students' skills in using technologies, and from evaluating the experience of distance learning in light of quality standards.

The results of these studies concluded that the distance learning experience has succeeded that direct learning is better in achievement and that there are obstacles facing this learning. Also, there is weakness among students in the use 
of modern technology, and the need to prepare an appropriate infrastructure for the success of distance learning. The current study has benefited from the methodology of previous studies, the selection of the sample, the preparation of the study tool, and the verification of its validity and stability, as well as, the benefit in how the results are presented and discussed. However, the current study differs from previous studies by dealing with the evaluation of the distance learning experience from the point of view of faculty members and students at Aqaba University College in Jordan.

By comparing the results of the current study with the results of previous studies. It is clear that not all studies dealt with one or more in evaluating the distance learning experience in the way the current study followed. According to the gender variable, the results of this study differed from the results of the Belbiesi's study (2017) which found the effectiveness of female students in using distance learning techniques and skills compared to male students.

\section{Questions of the Study}

This study attempted to answer the following questions:

- What is the degree of evaluation of the distance learning experience from the point of view of Aqaba University College teachers?

- What is the degree of evaluation of the distance learning experience from the point of view of Aqaba University College students?

- Are there statistically significant differences at the significance level $(\alpha \leq 0.05)$ in the degree of evaluating the distance learning experience due to the student's gender (male and female)?

\section{The importance of the Study}

The current study has theoretical importance that shows in its handling of an important topic which is the topic of distance learning in light of an exceptional circumstance experienced by the entire human community due to the Corona pandemic. The importance also appears in evaluating the distance learning experience adopted by all educational institutions in the Hashemite Kingdom of Jordan, especially higher education institutions in order to evaluate this experience by faculty members and students at Aqaba University College. The study also has an applied importance that appears in the statement of the responsible authorities of its findings, and the benefit of other researchers to conduct other studies on distance learning from different angles.

\section{Limitations of the Study}

The study limits itself as follows:

- Time limits: The study was conducted in the first semester of the academic year 2020/2021.
- Spatial boundaries: Aqaba University College.

- Human limits: all faculty members who teach students in the college, and a random sample of college students.

- The results of the study are determined by the extent of the validity and reliability of the study tools, and the objectivity of the respondents about the paragraphs of the questionnaire addressed to them.

\section{Definition of Terms}

Distance learning: Al-Zboon (2020) defines distance learning as a modern educational method that depends in its content on the difference in the place and the distance between the teacher and the study group, and it adopts educational programs that reach the students through multiple means of communication. Also, distance learning is defined procedurally: it is the programs developed by Aqaba University College to teach its students remotely, and through multiple means of communication.

Aqaba University College: It is a university college affiliated to Al-Balqa Applied University, which teaches hotel, maritime, and administrative disciplines for the bachelor's and diploma levels (intermediate university degree). It is located in the south of the Kingdom in the Aqaba Governorate.

\section{Method and Procedure Methodology}

The study followed the descriptive research method as it is the appropriate method to achieve its objectives.

\section{The study population and its sample}

All faculty members at Aqaba University College were selected and they were (42) teachers. A random sample of (333) male and female students were also selected and then (84) male and female students were chosen, 44 male and 40 female, representing the study sample.

\section{Tools of the study}

The current study requires the preparation of two tools which are a questionnaire addressed to members of the teaching staff, and a questionnaire addressed to students. The two questionnaires were prepared by reviewing the previous theoretical literature and some related previous studies. The number of paragraphs of the teachers' questionnaire were (19), while the number of paragraphs of the students' questionnaire were (17) items.

\section{The validity of the two questionnaires}

To verify the validity of the two questionnaires, they were presented in their initial form and given to a number of specialists in curricula and teaching from faculty members in Jordanian universities. 


\section{The stability of the two questionnaires}

To verify the stability of the teachers' questionnaire, a pilot sample was chosen outside the study sample from another college which is Ma'an University College where (10) male and female teachers were chosen who teach at Ma'an University College. The college is affiliated with Al-Balqa Applied University, and the questionnaire was applied to this sample twice with an interval. Two weeks' time between the two applications. Using the Pearson correlation coefficient, the reliability coefficient was (0.89). As for the stability of the students' questionnaire, an exploratory sample was chosen from outside the study sample as (20) male and female students were selected from the students of Aqaba University College. The students' questionnaire was applied to them twice, including a period of two weeks, and using the Pearson correlation coefficient, the reliability coefficient between the two applications was (0.87).

\section{Study Variables}

- Dependent variable: evaluation of the distance learning experience.

- The independent variable: the gender of the student and it has two levels: (male and female).

\section{Statistical scale}

To extract high, medium, and low rating estimates, the equation is used:

$\frac{3-1}{3}=0.67$

i.e.:

- $1.00-1.67 \rightarrow$ Low

- $1.68-2.35 \rightarrow$ Medium

- $2.36-3.00 \rightarrow$ High

\section{Statistical processing}

The arithmetic means and standard deviations were used to find out the degree of evaluation of the distance learning experience from the point of view of the faculty members. Also, the degree of evaluation of the experience itself from the students' point of view. The T-test was used to find out the significance of the differences between male and female students' responses regarding the degree of evaluation of the distance learning experience.

\section{Results AND discussion}

The results of the study are presented and discussed according to the following three questions:

Table 1: Arithmetic means, standard deviations, rank and estimate of the faculty members' questionnaire

\begin{tabular}{|c|c|c|c|c|}
\hline No & Questions & Mean & Standard deviations & Degree of Estimate \\
\hline 1 & Distance learning requires extra effort from the teacher. & 2.76 & .43 & High \\
\hline 2 & The distance learning process has made some students less interested. & 2.67 & .48 & High \\
\hline 3 & The activation of distance learning requires special professional skills. & 2.48 & 67 & High \\
\hline 4 & Distance learning increases students' achievement unrealistically. & 2.26 & .83 & Medium \\
\hline 5 & $\begin{array}{l}\text { The distance learning process reduced the mutual benefit in the teachers' } \\
\text { experiences. }\end{array}$ & 2.24 & .69 & Medium \\
\hline 6 & Distance learning helps to complete the prescribed curriculum. & 2.10 & .73 & Medium \\
\hline 7 & The teacher finds it difficult to download all the subject requirements. & 2.07 & .81 & Medium \\
\hline 8 & $\begin{array}{l}\text { The distance learning process makes the coordination process between } \\
\text { university institutions better. }\end{array}$ & 1.93 & .75 & Medium \\
\hline 9 & The distance learning process encouraged the student to learn on his/her own. & 1.90 & .76 & Medium \\
\hline 10 & The different methods of distance learning become more effective. & 1.86 & .72 & Medium \\
\hline 11 & Teacher becomes in distance learning more complex in the curriculum. & 1.81 & 67 & Medium \\
\hline 12 & The content in distance learning is often presented poorly. & 1.79 & .72 & Medium \\
\hline 13 & Distance learning makes the learning process easy. & 1.76 & .82 & Medium \\
\hline 14 & Distance learning has created a more transparent atmosphere in education. & 1.67 & .72 & Low \\
\hline 15 & Distance learning develops the personality of the student. & 1.62 & .79 & Low \\
\hline 16 & In distance learning, goals can be achieved in a better way. & 1.62 & .70 & Low \\
\hline 17 & $\begin{array}{l}\text { Distance learning makes the learning process more enjoyable for teachers and } \\
\text { students. }\end{array}$ & 1.55 & .67 & Low \\
\hline 18 & Distance learning makes students more follow-up. & 1.43 & .67 & Low \\
\hline \multirow[t]{2}{*}{19} & The distance learning process makes the students more open. & 1.43 & .59 & Low \\
\hline & Total & 1.94 & 0.70 & Medium \\
\hline
\end{tabular}


- What is the degree of evaluation of the distance learning experience from the point of view of the faculty members at Aqaba University College?

- To answer this question, the arithmetic means and standard deviations were extracted. Table (1) shows the items arranged in descending order according to the arithmetic mean.

It is noted from Table No. (1) that only two questions came with a degree of estimate (high) as the mean for each question was (2.76) and (2.67). Six questions came with a degree of estimate (low). As for the rest of the questions which numbered (11) they were graded (medium), and the total mean average was (1.94) which is graded (medium).

The advent of the overall average with a grade of (medium) may be attributed to the fact that the faculty members at Aqaba University College believe that distance learning is not a substitute for traditional learning in which the teacher is fully aware of the level of their students and that there is no substitute for classroom learning which it is the required interaction between the pillars of the educational process takes place.
With regard to the two items that were highly appreciated, namely: distance learning requires additional effort from the teacher, and the distance learning process has made some students less interested. The faculty members believe that distance learning requires preparation of a special kind and full knowledge of dealing with modern technologies. Diligent follow-up of students as well as the difficulty of assessing the level of the student, and the extent of their commitment. As for the advent of a question: the process of distance learning made students less interested, it may be attributed to the fact that the students' distance may reduce their sense of responsibility and encourage them to lack commitment which negatively affects their achievements.

A question came: The distance learning process makes students more open with the lowest mean average, meaning that faculty members see that distance learning reduces students' openness to others, especially openness to their colleagues, and that openness that is available and possible when the student interacts with their classmates. Also, a question came: Distance learning makes students more follow-up, with a (low) grade of appreciation as well. This

Table 2: Arithmetic means, standard deviations, rank and estimate of the students' questionnaire

\begin{tabular}{|c|c|c|c|c|}
\hline No & Questions & Mean & Standard deviations & Degree of Estimate \\
\hline 1 & I find it hard to fix problems when they happen with distance learning. & 2.17 & .83 & Medium \\
\hline 2 & I became in distance learning not interested in my lessons. & 1.99 & .83 & Medium \\
\hline 3 & $\begin{array}{l}\text { Distance learning made me more capable of self-learning (self- } \\
\text { reliance). }\end{array}$ & 1.98 & .81 & Medium \\
\hline 4 & I cannot interact with my classmates or my teacher in distance learning. & 1.98 & .84 & Medium \\
\hline 5 & Distance learning helps spread cheating. & 1.95 & .82 & Medium \\
\hline 6 & I can access the educational platforms easily. & 1.89 & .73 & Medium \\
\hline 7 & $\begin{array}{l}\text { I see that my teachers have become more committed to giving the } \\
\text { course in distance learning. }\end{array}$ & 1.88 & .75 & Medium \\
\hline 8 & $\begin{array}{l}\text { The way the lessons are presented makes the learning process easier } \\
\text { for me. }\end{array}$ & 1.83 & .69 & Medium \\
\hline 9 & I can permanently connect to the internet. & 1.80 & .72 & Medium \\
\hline 10 & $\begin{array}{l}\text { The educational tools used on the means of communication help me } \\
\text { to learn from a distance. }\end{array}$ & 1.77 & .70 & Medium \\
\hline 11 & $\begin{array}{l}\text { Technical teaching aids make me more interactive with my teacher } \\
\text { and classmates. }\end{array}$ & 1.76 & .74 & Medium \\
\hline 12 & With distance learning, I can organize my time in a better way. & 1.75 & .74 & Medium \\
\hline 13 & $\begin{array}{l}\text { Distance learning encouraged me to participate in questions and } \\
\text { answers, inquiry and discussion. }\end{array}$ & 1.73 & .77 & Medium \\
\hline 14 & Distance learning helps me gain new knowledge. & 1.71 & .74 & Medium \\
\hline 15 & $\begin{array}{l}\text { The way I communicate with my teacher through the platforms makes } \\
\text { me more comfortable. }\end{array}$ & 1.71 & .75 & Medium \\
\hline 16 & I would like to continue learning from a distance. & 1.62 & .81 & Low \\
\hline \multirow[t]{2}{*}{17} & $\begin{array}{l}\text { I see that learning has become more and more quality in distance } \\
\text { learning. }\end{array}$ & 1.54 & .75 & Low \\
\hline & Total & 1.83 & 0.72 & Medium \\
\hline
\end{tabular}


indicates that the faculty members see that learning reduces the student's follow-up to their lessons due to the absence of a direct supervisor. Among the questions that came with a (low) grade are: Distance learning makes learning more enjoyable for students and teachers. In the sense that faculty members do not see distance learning as enjoyable. This may be due to the fact that the fun is manifested in interaction with the teachers on the one hand and between the students themselves on the other hand. This cannot be done correctly except in the classroom.

Among the questions that came with a low grade is one: It is possible with distance learning to achieve the goals in a better way. That is, the goals in distance learning cannot be achieved in a better way, given that the goals especially the behavioral ones appear on the cognitive, emotional and skillful behavior of the student, and these goals seem to be difficult to measure from a distance. A (low) grade was also included in a question: Distance learning develops the students' personality. In the sense that teachers say that distance learning does not contribute to the development of the students' personality; the personality develops when the students communicate with their classmates directly as it is the university atmosphere that contributes to the development of the personality, and computer learning cannot play this role.

As for the other question that came with a (low) rating, it is the question that states: Distance learning has created a more transparent atmosphere in education which means that distance learning does not create such an atmosphere. In the sense that the university atmosphere is what makes the education process more transparent; for reasons related to the vitality of the university climate which makes students live the best types of relationships in the university community.

- What is the degree of evaluation of the distance learning experience from the point of view of Aqaba University College students?

To answer this question, the arithmetic means and standard deviations were extracted for each item of the students' questionnaire and these items were arranged in descending order according to the arithmetic means. Table (2) shows that.

It is noted from Table (2) that all the evaluation questions of the distance learning experience from the students' point of view came with a grade of (medium) except for two questions: rating (low).

The overall degree of appreciation was (medium). This means that the students do not prefer distance learning and in this case they are in harmony with their professors in the degree of assessment, although the teachers evaluated the experience with a total arithmetic average slightly higher than the average of the students.

None of the questions in the students' questionnaire came with a high grade which means that the students did not prefer distance learning in general. For example, they find it difficult
Table 3: T-test according to the sex variable

\begin{tabular}{lll}
\hline T. value & Degree of freedom & Sig. \\
\hline 15.25 & 73.71 & 0.000 \\
\hline
\end{tabular}

to fix the defect when it occurs in distance learning and they become disinterested in their lessons. This explains that the students did not have enough ability to deal with modern technologies, and that they are not subject to follow-up by their teachers, so they became less interested in their lessons.

As for the two questions that came with a (low) grade, they are: I see that learning has become more quality in distance learning, and I want to continue to learn from a distance. This means that learning in the distance learning experience has become bad learning and that the student refuses to continue to be learning remote. This may be due to the fact that students feel that learning is good when it is direct, in interaction with the professor and students. As for the refusal to continue with distance learning, it may be attributed to the fact that this prevents them from meeting their colleagues in a university atmosphere that the student must live in, in addition to that most students may feel Embarrassed to communicate with their professors through the available means of communication.

- Are there statistically significant differences at the significance level $(0.05 \leq \alpha)$ in the degree of evaluation of the distance learning experience due to the student's gender (male, female)?

To answer this question, the researcher used t. test. (Table 3 ) shows this.

It is noticed from Table (3) that the (calculated T) value was (15.25) which is a significant value at the significance level $(0.000)$ which means that there is a difference attributed to the sex variable in favor of males in evaluating the distance learning experience. The reason may be that males are more preferable for female distance learning. Students see that distance learning is not a problem for them; they can meet with their friends and colleagues at any time, while it may not be available for female students, who prefer to learn on campus, because it gives them the opportunity to meet with their colleagues and colleagues. In addition, female students may be more eager to learn than male students, as this requires that learning be direct, and there may be another reason due to female students feeling more embarrassed in communicating with their professors.

\section{Conclusion}

In conclusion, after the researchers presented the research problem which was represented in evaluating the distance learning experience from the point of view of faculty members and students at Aqaba University College due to the great importance in this period in which the whole world suffers 
from the spread of the (Covid-19) epidemic, and the difficulty of Teaching in a face-to-face manner. Distance teaching/ learning has become a central imperative to solve the problem of education in universities. The researchers worked on posing the problem and followed the descriptive approach to reach results which hoped will contribute to solving the problem, which are: Education requires additional effort from the teacher and their knowledge of modern technologies and courses, and the students' opinions in the distance teaching process varied between the validity of this method, its invalidity and its feasibility, and the recommendation came. By providing the infrastructure and using the available technological means for communication, and conducting other studies on this problem. We have presented this modest effort in the hope that it will be generalized to international educational institutions; to be followed up, developed, and the necessary studies conducted. It is nothing but little effort and increased haste, and shortcomings are among the natures of human beings.

\section{Recommendations}

In light of the results, the following can be recommended:

- Developing the distance learning process by providing the appropriate infrastructure for this type of learning.

- 2-To develop awareness among students of the importance of using modern means of communication in their various forms.

- Conducting other studies to study the problems of distance learning, and ways to treat them.

\section{References}

Affouneh S, \& Salha S, \& Khlaif ZN. (2020) Designing Quality E-Learning Environments for Emergency Remote Teaching in Coronavirus Crisis. Interdisciplinary Journal Virtual Learning Medical Sciences.11 (2), 1-3

Al-Akhras, Y. (2018) The Impact of Applying the E-Learning Strategy on Academic Achievement in Mathematics in Basic Classes in the Capital Governorate from the Perspective of Mathematics Teachers, Journal of Educational Sciences Studies. 45 (4), 70-80

Al-Azzam, M. F. M. (2017) Quality assurance in open and distance learning. Journal of Education. 69 (158), 1-18.

Al-Hassan, I. I. K. (2014) The extent of the contribution of educational technology to the distance learning program in Sudanese universities. Journal of Educational Studies, Faculty of Education, International Africa University. No.3, 118-158.

Al-Mahmadi, G. A. T. (2018) Evaluating the reality of using the electronic learning system (EMES) in the distance education program at King Abdulaziz University from the students' point of view. Journal of the College of Basic Education for Educational and Human Sciences. (39), 177-196.

Al-mula, A. A. (2016) Evaluating the distance education experience at the Malaysian University and the College of Education for females according to the quality standards taken from the Quality Assurance Agency for Higher Education - Britain. International Journal of Educational Research, Volume 39, UAE

Al-Zboon, K. O. M. (2020) The effectiveness of distance learning compared to direct education in the achievement of first-grade students in the Arabic language subject in Jordan. Arab Journal of Specific Education. 4 (14), 201-220.

Awad, M. S., \& Halles \&., Musa. S. (2015) The trend towards distance learning technology and its relationship to some variables among graduate students in Palestinian universities. Al-Aqsa Magazine, College of Education. 19(1), 219-256.

Basilaia, G., \& Kvavadze, D. (2020) Transition to online education in schools during a SARS-CoV-2 coronavirus (COVID-19) pandemic in Georgia. Pedagogical Research. 5(4), 1-9.囚

Belbeisi, Mona Abdel Kader. (2017) The effectiveness of Al-Quds Open University students in the Salfit educational area in using distance learning skills and technologies. Journal of Palestinian Journal of Open Learning \& E-Learning. 1(1), 355-402.

Kamal, S. A. (2002) Ensuring good quality in open and distance learning. Journal of Al-Quds Open University for Research and Studies. No.1, 25-50.

Visande, J. C. (2014) Developing Critical Thinking Skills among Education Students Through Formative Education. International Journal for Cross-Disciplinary Subjects in Education (IJCDSE). 5(4), 1783-1789.

Yulia, H. (2020) Online Learning to Prevent the Spread of Pandemic Corona Virus in Indonesia. English Teaching Journal. 11(1), 48-56 